\title{
Objective Evaluation of Soy Sauce by Statistical Analysis of GC Profiles
}

\author{
Tetsuo Aishima
}

\author{
Noda Institute for Scientific Research, Noda-shi, Chiba-ken, Japan \\ Received May 1, 1979
}

\begin{abstract}
The relationships between GC data of volatiles and sensory score of the heighest grade of soy sauce (Tokusen shoyu) were analyzed by multivariate analyses. Samples belonging to four brands could be unambiguously classified into the correct brands and the statistical distance among them suggested a close relation with sensory evaluation. The precise predictive equations for the aroma quality were calculated from GC data and sensory evaluation by multiple regression analysis. Eight principal components were extracted from $39 \mathrm{GC}$ peaks as significant factors constituting soy sauce aroma. The second PC can explain $58 \%$ of the variation among total variation contained in the sensory score. Discriminant functions on the basis of the 8 PCs can clearly classify all samples.
\end{abstract}

Regarding soy sauce aroma, so many efforts have been concentrated to identify the unique aroma. Despite more than 170 aroma compounds identified so far, no one single compound can represent the soy sauce aroma. ${ }^{1 \sim 4)}$ Consequently, soy sauce aroma was considered as an integrated effect of many aroma compounds and the relationship between sensory analysis and GC data of the volatiles was investigated by using multivariate analyses. ${ }^{5 \sim 7}$ ) These results clearly indicated that aroma of soy sauce is ascribed to the total effects of whole aroma compounds and the quality can be objectively and precisely evaluated on the basis of GC data of the volatiles.

Soy sauce is classified into three groups according to the quality standard on the basis of the contents and making processes. The highest grade in the fancy grade is defined as extra fancy grade (Tokusen shoyu) which containes more than $1.7 \%(\mathrm{w} / \mathrm{v})$ of total nitrogen contents and made by purely fermented process.

In this report, four brands of such top grades of soy sauce were selected as samples and relationships between GC profiles of aroma concentrates of these samples and quality evaluated by sensory tests were analyzed by three kinds of multivariate analyses. Then factors constituting soy sauce aroma were extracted from the
GC data by principal component analysis.

Concerning computer evaluation of aroma quality on the basis of their GC profiles, Powers and Keith ${ }^{8)}$ successfully differentiated cola beverages by discriminant analysis of $\mathrm{GC}$ data. Milutinovic et al..$^{91}$ classified tomato products by the same methods. Dravnieks et al. ${ }^{10}$ ) and Dravnieks and Watson ${ }^{11)}$ classified corn odor in agreement with sensory evaluation and GC data by discriminant analysis of head space volatiles. Bednarczyk and $\mathrm{Kramer}^{12,13)}$ successfully applied multiple regression analysis on the GC data of ginger essential oil and sensory evaluation. Recently, Jenings, ${ }^{14)}$ Carter and Cornell, ${ }^{15}$ ) Lindsay, ${ }^{16)}$ and Williams et $a l^{17 /}$ reported and discussed several aspects of objective measurements of flavor quality. Tanaka and Saito ${ }^{18)}$ applied multiple regression analysis and principal component analysis on the chemical and sensory analysis of soy sauce but they could not find direct relationships between the two.

\section{EXPERIMENTAL}

Samples and sensory tests. The four brands (A, B, $C$, and D) of extra fancy grade soy sauce were purchased monthly in the market for 20 months. Therefore the total number of samples amounted to 80 . Usually extra fancy grade of soy sauce is made of high grade raw materials and the constituents are richer than those 
in other grades. About $20 \mathrm{ml}$ of each sample contained in 2 liter glass bottle was poured into a plate and then evaluated by sniff test and order from one to four according to their preference. The number of sensory test panel in Kikkoman Shoyu Co., Ltd. varied from 160 to 109 and, therefore, the average order was used as the sensory score in the following statistical analyses.

Sample preparation and GC analysis. Fifty $\mathrm{ml}$ of soy sauce sample was distilled under reduced pressure at 15 Torr and $45^{\circ} \mathrm{C}$. The distillate condensed in traps cooled with ice-water and dry ice-acetone was combined. Twenty five $\mathrm{ml}$ of the resulting distillate was treated with $5 \mathrm{ml}$ of dichloromethane and one $\mathrm{ml}$ of dichloromethane containing $80 \mathrm{ppm}$ of $n$-undecane for $5 \mathrm{~min}$. Then dichloromethame extract was concentrated under a reduced pressure at 30 Torr to ca. $10 \mu \mathrm{l}$. During the concentration, trace of water was frozen out and eliminated from the extract. About two $\mu 1$ of the concentrates was injected into $\mathrm{GC}$ and analyzed by using JEOL JGC-1100 gas chromatograph under conditions as below. Columns; glass, packed with 20\% PEG 20M/Chromosorb W AW-DMCS, $3 \mathrm{~m} \times 3 \mathrm{~mm}$ I.D., column temperature; $50 \sim 210^{\circ} \mathrm{C}$ $\left(3^{\circ} \mathrm{C} / \mathrm{min}\right)$, injection temperature; $250^{\circ} \mathrm{C}$, carrier gas; $\mathrm{N}_{2}(40 \mathrm{ml} / \mathrm{min})$, detector; FID dual frame system. Gas chromatograms were recorded with JEOL JR-252A two pen recorder and the ratio of two pens was settled as one to ten. The height of selected peaks was measured. Then each peak height was converted into six different forms expressed in Table $\mathrm{V}$ in order to compare the fitness for the hypothetical mathematical models. Transformations were carried out by FORTRAN programs and statistical analysis was performed in online system.

Statistical analysis. Three kinds of multivariate analyses were performed by UNIVAC 1108 computer system.

(i) Discriminant analysis

A discriminant function is generally expressed as an eq. (I),

$$
Z=a_{1} x_{1}+a_{2} x_{2}+\cdots+a_{i} x_{i}+\cdots+a_{m} x_{m}
$$

where $x_{i}$ means $i$ th peak on gas chromatograms. In the equation, $Z$ is calculated in order to maximize the ratio of between-group variation to within-group variation. If there are $g$ groups in the samples, $(g-1)$ discriminant functions can be calculated. The generalized distance calculated from such disctance is called as Mahalanobis $D^{2}$. Canonical variables were calculated in order to discriminate samples on the basis of a two dimensional space. Stepwise discriminant analysis was performed by BMD07M program. ${ }^{19)}$

(ii) Multiple regression analysis

A multiple regression model is generally expressed as an eq. (II).

$$
Y=\beta_{1} X_{1}+\beta_{2} X_{2}+\cdots+\beta_{i} X_{i}+\cdots+\beta_{m} X_{m}+\alpha+e
$$

In the eq. (II), $X_{i}$ and $Y$ respectively represent GC peaks and sensory score. $\alpha, \beta_{i}$, and $e$ are designated a constant, partial regression coefficient, and error, respectively. $\alpha$ and $\beta_{i}$ are calculated by a linear least squares method. A correlation coefficient between sensory score $(Y)$ and score estimated from culculated multiple regression model is designated as a multiple correlation coefficient $(R) . \quad K^{2}$ is called a multiple determination coefficient and expresses the explained ratio of variation in $Y$ from the multiple regression model. This analysis was performed by BMD03R program. ${ }^{20)}$

Contributing proportion of each peak for the multiple regression model was calculated by applying a method described by Barylko-Pikielna and Metelski. ${ }^{21)}$ Stepwise multiple regression analysis was performed by BMD02R program. ${ }^{22)}$

(iii) Principal component analysis

Principal components $\left(Z_{k}\right)$ are calculated from the eq. (III).

$$
\begin{aligned}
& Z_{1}=a_{11} x_{1}+a_{12} x_{2}+\cdots+a_{1 i} x_{i}+\cdots+a_{1 m} x_{m} \\
& Z_{2}=a_{21} x_{1}+a_{22} x_{2}+\cdots+a_{2 i} x_{i}+\cdots+a_{2 m} x_{m}
\end{aligned}
$$

where $a_{k i}$ is designated as eigen vector under the condition of the sum of squares of $a_{k i}$ is one. Variance in $Z_{1}$ is maximized among all principal components and correlation between $Z_{k}$ and $Z_{k+1}$ is settled zero. Therefore principal component analysis can be considered as the method which can contract information contained in GC data into principal components in order to minimize the loss of information. A correlation coefficient between each peak and principal component is designated as factor loading. This analysis was performed by BMD01M program. ${ }^{23)}$

\section{RESULTS AND DISCUSSION}

\section{Sensory and $G C$ analysis}

The average and standard deviation of sensory score in 20 sensory tests are shown in Table I. In the sensory tests, the standard deviation of each brand clearly indicated that the quality difference among the four brands was distinguished by the sensory panel. Typi-

Table I. The Average and Standard DeViation of SENSORY SCORE FOR FOUR BRANDS

\begin{tabular}{ccc} 
Brand & $\begin{array}{c}\text { Average sensory } \\
\text { score }\end{array}$ & $\begin{array}{c}\text { Standard } \\
\text { deviation }\end{array}$ \\
\hline A & 1.78 & .12 \\
B & 1.90 & .12 \\
C & 2.66 & .09 \\
D & 3.66 & .09 \\
\hline
\end{tabular}




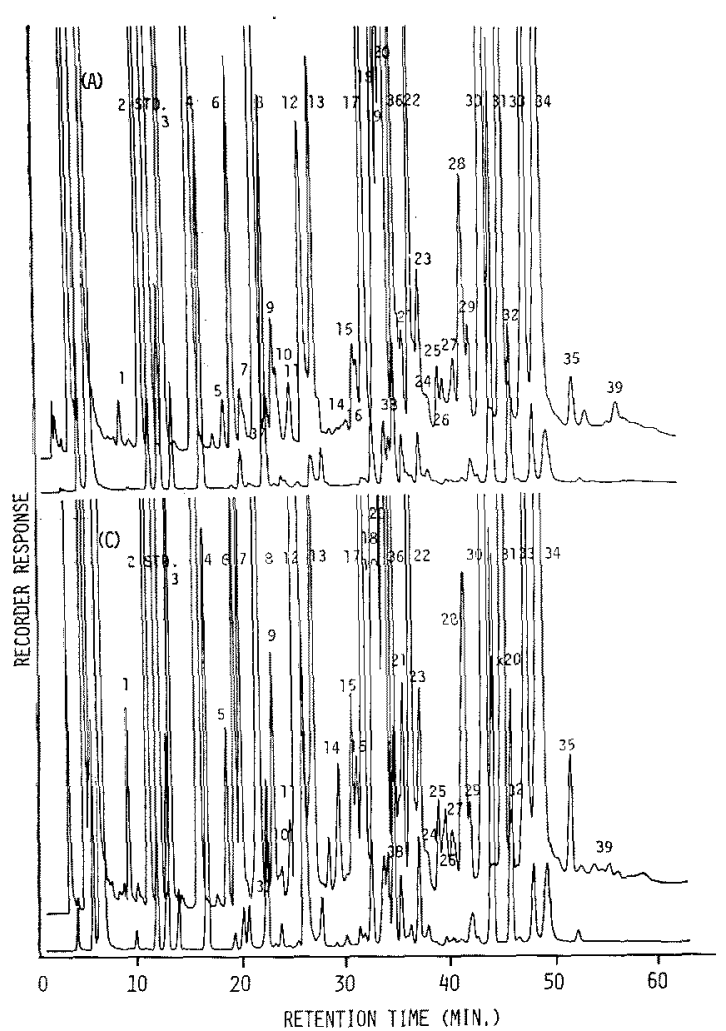

Fig. 1. Gas Chromatograms of Aroma of Extra Fancy Grade Soy Sauce.

Table II. Correlation Coefficients $(r)$ BetWeEn the SEnsory SCORE AND PEAK QUANTITY (\%)

\begin{tabular}{cccccc}
\hline $\begin{array}{c}\text { Peak } \\
\text { number }\end{array}$ & $r$ & $\begin{array}{c}\text { Peak } \\
\text { number }\end{array}$ & $r$ & $\begin{array}{c}\text { Peak } \\
\text { number }\end{array}$ & $r$ \\
\hline 1 & -.063 & 14 & -.164 & 27 & -.183 \\
2 & -.111 & 15 & $.682^{* *}$ & 28 & -.142 \\
3 & $-.596^{* *}$ & 16 & .154 & 29 & $.255^{*}$ \\
4 & .230 & 17 & $-.537^{* *}$ & 30 & $.455^{* *}$ \\
5 & -.100 & 18 & $-.388^{* *}$ & 31 & $-.296^{* *}$ \\
6 & .180 & 19 & $.635^{* *}$ & 32 & $.373^{* *}$ \\
7 & $-.371^{* *}$ & 20 & $-.281^{*}$ & 33 & .155 \\
8 & -.143 & 21 & -.174 & 34 & $-.413^{* *}$ \\
9 & $-.550^{* *}$ & 22 & $.649^{* *}$ & 35 & $.499^{* *}$ \\
10 & $-.696^{* *}$ & 23 & $-.415^{* *}$ & 36 & $.428^{* *}$ \\
11 & $-.871^{* *}$ & 24 & -.201 & 37 & $-.593^{* *}$ \\
12 & .047 & 25 & $-.318^{* *}$ & 38 & $-.331^{* *}$ \\
13 & $-.549^{* *}$ & 26 & -.105 & 39 & -.642 \\
\hline$* 5$
\end{tabular}

cal gas chromatograms of brands $\mathrm{A}$ and $\mathrm{C}$ were shown in Fig. 1. According to the results of previous analysis, ${ }^{5 \sim 7} 39$ peaks indicated with number were selected as variables for the following statistical analysis. Samples belonging to different four brands could be distinguished by comparing the GC profiles.

Each peak height was transformed to per cent on the basis of sum of whole peak height. Correlation between peak quantity and the sensory score are shown in Table II. Peaks with negative correlation mean that such peaks contributed to the preferable aroma, on the contrary, peaks with positive correlation conduce to the unpleasant odor.

\section{Discriminant analysis}

The eighty gas chromatograms in which each peak was converted to per cent were analyzed by discriminant analysis. The significant difference among the four brands was observed as shown in Table III. The unambiguous classification on the basis of GC data was shown in Table IV and the actual distance

TABle III. F-Matrix Among Four Brands Calculated at Step 38

\begin{tabular}{crrr}
\hline & \multicolumn{3}{c}{ Brand } \\
\cline { 2 - 4 } & $\mathrm{A}$ & $\mathrm{B}$ & $\mathrm{C}$ \\
\hline $\mathrm{B}$ & $24.25^{* *}$ & & \\
$\mathrm{C}$ & $79.90^{* *}$ & $109.03^{* *}$ & \\
$\mathrm{D}$ & $70.12^{* *}$ & $63.59^{* *}$ & $83.66^{* *}$ \\
\hline ** $\mathrm{P}<0.01, F(38,39 ; 0.01)=2.13$ &
\end{tabular}

Table IV. Number of Samples Classified INTO BRANDS AT STEP 38

\begin{tabular}{crrrr} 
& \multicolumn{4}{c}{ Brand } \\
\cline { 2 - 5 } Brand & A & B & C & D \\
\hline A & 20 & 0 & 0 & 0 \\
B & 0 & 20 & 0 & 0 \\
C & 0 & 0 & 20 & 0 \\
D & 0 & 0 & 0 & 20 \\
\hline
\end{tabular}

between two brands was calculated as Mahalanobis distance as shown in Fig. 2. Then canonical variables for each sample were calculated and each sample was plotted on the first $(X)$ and second $(Y)$ canonical variables in order to examine two dimensional discrimination of samples as shown in Fig. 3. Both in Figs. 2 and 3, brands A and B located closely. These scattergrams show that evaluation of quality difference in the sensory tests was 


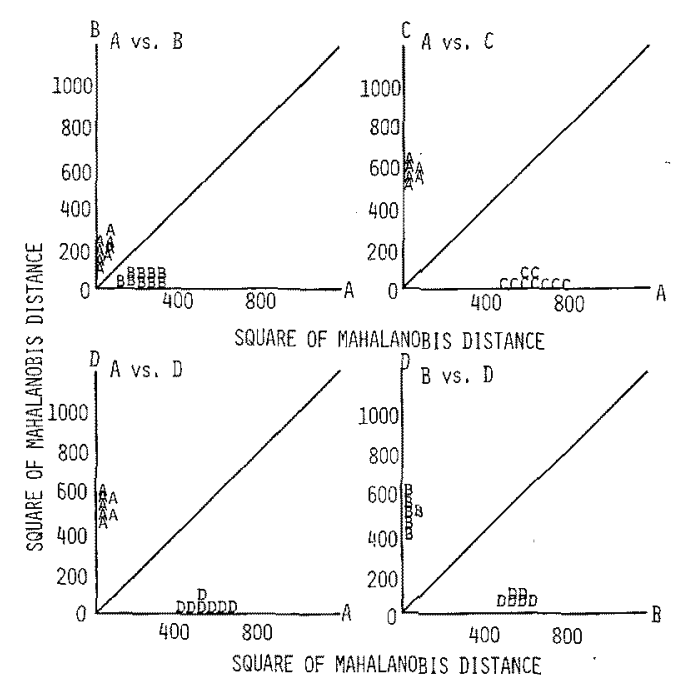

FIG. 2. Discrimination Among Four Brands of Extra Fancy Grade Soy Sauce.

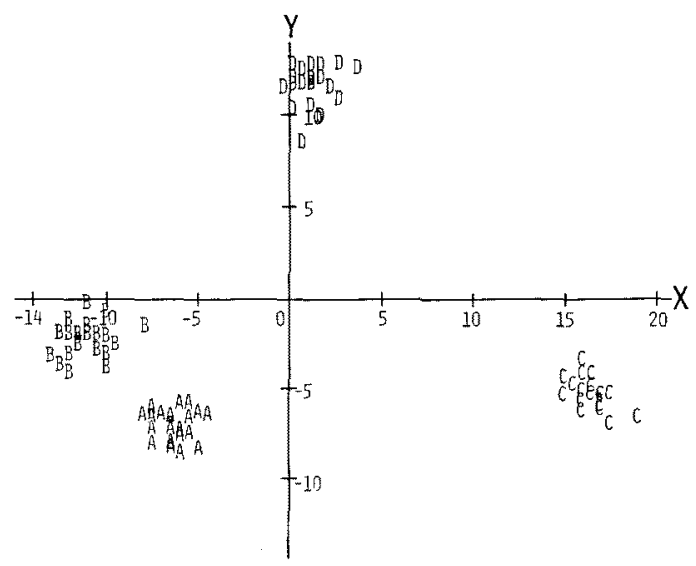

FIG. 3. Canonical Plot of Samples of Extra Fancy Grade Soy Sauce.

performed on the basis of the different standards in the discriminant analysis of GC profiles because the positions of the most disliked brand $D$ with respect to the preferred brands $A$ and $B$ are nearer than those of $C$ relative to $A$ and $B$.

\section{Multiple regression analysis of $G C$ data and sensory data}

The relationships between the sensory score and $\mathrm{GC}$ data were analyzed by multiple regression analysis. GC data was transformed into 6 different forms in order to compare the fitness on a linear equation model as shown in Table V. The most precise fitness was cal-
Table V. Summary Table of Multiple REGRESSION ANALYSIS

\begin{tabular}{lcccc}
\hline Transformation & $R$ & $R^{2}$ & $F$-Value & $\begin{array}{c}\text { Precision } \\
\text { order }\end{array}$ \\
\hline$X_{i} / \mathrm{STD}{ }^{*}$ & .988 & .977 & $42.65^{* *}$ & 5 \\
$\sqrt{X_{i} / \mathrm{STD} .}$ & .991 & .981 & $54.08^{* *}$ & 4 \\
$\sqrt{X_{i} / \Sigma X_{i}}$ & .991 & .983 & $58.09^{* *}$ & 1 \\
$\ln \left(X_{i} / \mathrm{STD}+1.0\right)$ & .987 & .974 & $38.85^{* *}$ & 6 \\
$\ln \left(X_{i} / \Sigma X_{i}+1.0\right)$ & .991 & .982 & $54.80^{* *}$ & 3 \\
$\operatorname{Sin}^{-1} X_{i} / \Sigma X_{i}$ & .991 & .982 & $55.37^{* *}$ & 2 \\
\hline$* \quad$ Peak height of $n$-undecane. \\
$* * 20.01, F(39,40 ; 0.01)=2.11$
\end{tabular}

culated from square roots of each peak ratio to the sum of whole peaks and the multiple determination coefficient showed $98.3 \%$ of variation in the sensory score could be explained on the basis of GC data. The ratio of average sensory score of $\mathrm{D}$ to that of $\mathrm{A}$ was 2.06 and it seems rather small comparing the difference in the GC data. That might be the reason why the square roots transformation was effective to linearize GC data for the sensory score.

Stepwise multiple regression analysis was applied on the GC data and sensory score in order to calculate more predictive equations consist of smaller number of peaks and multiple regression models computed at step 5 and 10 are shown in Fig. 4. All peaks entered into both equations showed statistical significance, A multiple regression model computed at step 5 could explain $90 \%$ of variation contained in the sensory score. Analysis of variance for these two regression models, $F$-value, showed the highest among statistical analyses for GC data of soy sauce.

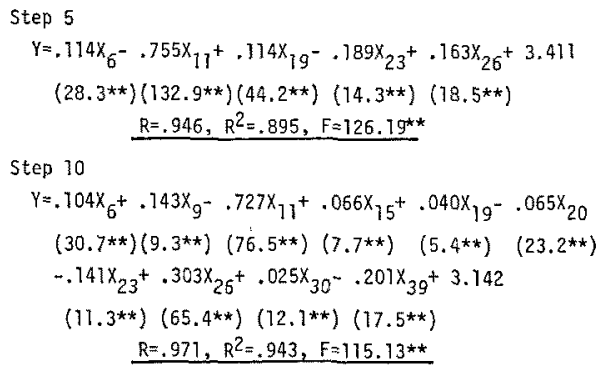

FIG. 4. Multiple Regression Models Computed at Step 5 and 10.

$* * P<0.01, F(5,74 ; 0.01)=3.26, F(10,69 ; 0.01)=2.63$ 
The changes in $R, R^{2}$, and standard error of estimate in stepwise multiple regression analysis are shown in Fig. 5. The standard error of estimate decreased progressively with each step and it reached minimum value of 0.126 at step 26 with 24 peaks.

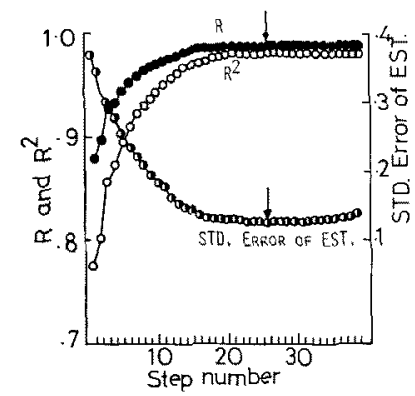

FIG. 5. Changes in Multiple Correlation Coefficients $(R)$, Coefficients of Multiple Determination $\left(K^{2}\right)$, and Standard Error of Estimate in Stepwise Multiple Regression Analysis.

$\downarrow$, Removal of variable from a multiple regression model.

\section{Contributing proportion of each peak}

Relative importance of each peak in the multiple regression model computed from the square roots transformed peak ratio to the sum of whole peaks is shown in Table VI. Peak 11; trans-2-hexen-1-ol, peak 3; butanol, and peak $39 ; 2$, 6-dimethoxy phenol highly contri-

Table VI. Contributing Proportion (Pi\%) of Each Peak Computed From Square Roots of Peak Ratio to the Sum of Whole Peaks

\begin{tabular}{rccccc}
\hline $\begin{array}{l}\text { Peak } \\
\text { number }\end{array}$ & Pi & $\begin{array}{c}\text { Peak } \\
\text { number }\end{array}$ & Pi & $\begin{array}{c}\text { Peak } \\
\text { number }\end{array}$ & Pi \\
\hline 1 & .17 & 14 & .15 & 27 & .29 \\
2 & .31 & 15 & $11.99^{*}$ & 28 & 1.44 \\
3 & $4.79^{* *}$ & 16 & .00 & 29 & .34 \\
4 & 1.04 & 17 & $7.85^{* *}$ & 30 & $2.05^{*}$ \\
5 & 1.08 & 18 & $2.43^{* *}$ & 31 & $.90^{* *}$ \\
6 & .21 & 19 & $1.51^{*}$ & 32 & $1.71^{*}$ \\
7 & $.77^{* *}$ & 20 & 1.95 & 33 & 4.04 \\
8 & 1.51 & 21 & 2.52 & 34 & $.97^{* *}$ \\
9 & $3.74^{* *}$ & 22 & $.02^{*}$ & 35 & $12.60^{*}$ \\
10 & $1.37^{* *}$ & 23 & $4.24^{* *}$ & 36 & $3.39^{*}$ \\
11 & $10.25^{* *}$ & 24 & .09 & 37 & $1.87^{* *}$ \\
12 & .10 & 25 & $.95^{* *}$ & 38 & $.31^{* *}$ \\
13 & $3.03^{* *}$ & 26 & 1.19 & 39 & $4.09^{* *}$ \\
\hline$*$ & $0<r ;(P<0.01)$, & & & \\
$* *$ & $r<0 ;(P<0.01)$ & & &
\end{tabular}

buted to the preferable aroma with increase in the quantity. On the contrary, peak 15; iso-butyric acid, peak 33 ; 4-ethyl guaiacol, and peak $35 ; p$-ethylphenol make the quality of aroma inferior with increase in the quantity. These opposite effects of aliphatic alcolhols from fatty acids and phenolic compounds seemed to be ascribed to the difference of yeast in the mash stage. Namely, aliphatic alcohols and phenolic compounds are respectively generated from Saccharomyces and Torulopsis. $^{24)}$

\section{Principal component analysis of $G C$ data}

Per cent transformed GC data was analyzed by PCA in order to extract efficient factors for aroma contained in 39 peaks. Eight factors showed larger than 1.0 in eigen values were extracted as shown in Table VII and the cumulative proportion up to the eighth $\mathrm{PC}$ was

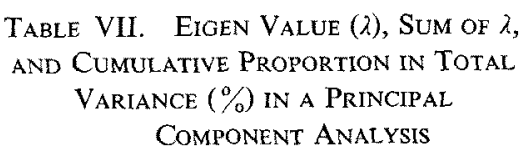

Table VII. Eigen Value ( $\lambda$ ), Sum of $\lambda$, and Cumulative Proportion in Total VARIANCE $(\%)$ In A PrInCIPAL COMPONENT ANALYSIS

\begin{tabular}{crrc}
$\begin{array}{c}\text { Principal } \\
\text { component } \\
\left(Z_{i}\right)\end{array}$ & $\begin{array}{l}\text { Eigen } \\
\text { value }\end{array}$ & Sum of $\lambda$ & $\begin{array}{c}\text { Cumulative } \\
\text { proportion }\end{array}$ \\
\hline 1 & 11.53 & 11.53 & 30 \\
2 & 7.57 & 19.10 & 49 \\
3 & 5.19 & 24.28 & 62 \\
4 & 3.21 & 27.49 & 70 \\
5 & 2.26 & 29.75 & 76 \\
6 & 1.73 & 31.48 & 81 \\
7 & 1.30 & 32.77 & 84 \\
8 & 1.01 & 33.78 & 87 \\
9 & .79 & 34.57 & 89 \\
10 & .62 & 35.19 & 90 \\
\hline
\end{tabular}

$87 \%$. Namely, total variance contained in 39 peaks could be contracted into $8 \mathrm{PCs}$ with $13 \%$ loss of variance. Factor loading on the major five PCs and communality up to the five PCs are shown in Table VIII. Peaks with large absolute factor loading show that they have close relation to the PCs. Peak $31 ; 2-$ acetylpyrrole and peak 4; 3-methyl butanol showed the closest correlation to the first PC in the negative and positive factor loading, respectively. Despite of these factor loadings, 
Table VIII. Factor Loading and Communality Matrix

\begin{tabular}{|c|c|c|c|c|c|c|}
\hline \multirow{2}{*}{ Peak number } & \multicolumn{5}{|c|}{ Principal component } & \multirow{2}{*}{ Communality } \\
\hline & 1 & 2 & 3 & 4 & 5 & \\
\hline 1 & .196 & .305 & .644 & -.261 & .645 & .618 \\
\hline 2 & .665 & .539 & .241 & -.262 & .029 & .860 \\
\hline 3 & .282 & .793 & -.070 & -.414 & .157 & .909 \\
\hline 4 & .781 & .207 & .214 & -.004 & .208 & .742 \\
\hline 5 & -.804 & -.195 & .366 & .063 & .082 & .830 \\
\hline 6 & .513 & .355 & .382 & .307 & -.319 & .732 \\
\hline 7 & -.684 & .145 & .455 & -.310 & .050 & .795 \\
\hline 8 & .355 & .558 & -.109 & .627 & -.186 & .877 \\
\hline 9 & -.412 & .565 & .417 & -.311 & -.013 & .759 \\
\hline 10 & .001 & .689 & -.224 & -.545 & .113 & .834 \\
\hline 11 & -.351 & .815 & -.166 & -.220 & .122 & .877 \\
\hline 12 & -.403 & -.250 & .634 & -.085 & .137 & .652 \\
\hline 13 & -.624 & .573 & .007 & .342 & -.187 & .869 \\
\hline 14 & -.167 & -.316 & .277 & -.372 & -.179 & .375 \\
\hline 15 & .619 & -.397 & .509 & .043 & -.080 & .808 \\
\hline 16 & -.399 & -.059 & .574 & .389 & -.276 & .719 \\
\hline 17 & -.795 & .404 & -.076 & .337 & -.076 & .921 \\
\hline 18 & -.943 & .096 & .145 & .121 & -.052 & .938 \\
\hline 19 & .027 & -.765 & -.101 & -.125 & -.125 & .627 \\
\hline 20 & -.710 & .108 & .533 & .169 & .013 & .829 \\
\hline 21 & -.889 & -.114 & .089 & .233 & -.051 & .868 \\
\hline 22 & .426 & -.652 & .062 & -.219 & .123 & .673 \\
\hline 23 & -.724 & .018 & -.140 & -.366 & -.056 & .681 \\
\hline 24 & -.584 & -.132 & -.484 & -.255 & -.227 & .711 \\
\hline 25 & -.869 & -.004 & -.106 & -.058 & -.257 & .836 \\
\hline 26 & -.769 & -.238 & -.285 & .005 & -.084 & .736 \\
\hline 27 & -.272 & .031 & -.760 & .090 & -.063 & .664 \\
\hline 28 & -.832 & -.326 & .015 & -.151 & .133 & .849 \\
\hline 29 & .281 & -.212 & -.404 & .474 & .353 & .637 \\
\hline 30 & -.068 & -.718 & -.382 & .176 & .344 & .815 \\
\hline 31 & -.934 & -.150 & .008 & -.007 & .139 & .913 \\
\hline 32 & -.199 & -.722 & -.130 & .063 & .449 & .783 \\
\hline 33 & .274 & -.269 & -.382 & -.498 & -.540 & .833 \\
\hline 34 & -.284 & .009 & .016 & -.468 & 680 & .763 \\
\hline 35 & .250 & -.532 & -.306 & -.390 & -.586 & .935 \\
\hline 36 & .159 & -.379 & .614 & .046 & .105 & .559 \\
\hline 37 & -.087 & .744 & -.032 & -.037 & -.015 & .564 \\
\hline 38 & .226 & .447 & -.530 & .251 & .265 & .666 \\
\hline 39 & -.401 & .408 & -.605 & -018 & .082 & .700 \\
\hline
\end{tabular}

clear explanation for each PC could not be obtained because of lack of information for each peak origin. Judging from Table II and Table VIII, peaks correlated highly to the sensory score show the large factor loadings for the second PC rather than them for the first PC. Such a tendency suggested more significant contribution of the second $\mathrm{PC}$ for the aroma quality than that of the first $\mathrm{PC}$.
Relation between PCs and sensory score

In order to examine the relationships between the aroma quality and sensory score, the first and second PCs were plotted against the sensory score as shown in Fig. 6. However, samples belonging to brand $\mathrm{A}$ and $\mathrm{B}$ could not be divided on these PCs, samples of either of brands $\mathrm{C}$ and $\mathrm{D}$ assembled separate groups. The second PC showed the closer relation to 

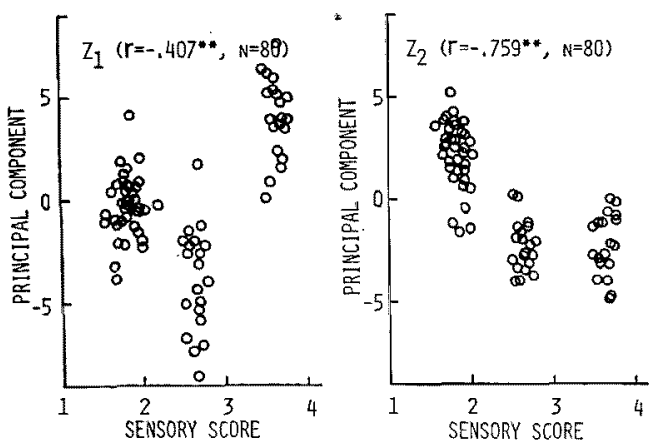

FIG. 6. The Sensory Score vs. the First Principal Component $\left(Z_{1}\right)$ and Second Principal Component $\left(Z_{2}\right)$.

** $P<0.01$.

Table IX. Relationships between the Principal COMPONENTS $\left(Z_{i}\right)$ AND Sensory SCORE

ANALyzed By Multiple Regression

ANALYSIS

\begin{tabular}{|c|c|c|c|}
\hline$Z_{i}$ & $\begin{array}{c}\text { Correlation } \\
(r) \\
Z_{i} \text { vs. } Y\end{array}$ & $\begin{array}{l}\text { Contributing } \\
\text { proportion } \\
\quad(\%)\end{array}$ & $F$-Value \\
\hline 1 & $-.407 * *$ & 16.56 & $108.29 * * *$ \\
\hline 2 & $-.759 * *$ & 57.60 & $376.59 * * *$ \\
\hline 3 & .178 & 3.16 & $20.61^{* * *}$ \\
\hline 4 & $-.233^{*}$ & 5.41 & $35.36^{* * *}$ \\
\hline 5 & .207 & 4.29 & $27.99 * * *$ \\
\hline 6 & -.029 & .08 & .55 \\
\hline 7 & .114 & 1.31 & $8.55^{* * *}$ \\
\hline 8 & .089 & .72 & $4.71 * * *$ \\
\hline \multicolumn{4}{|c|}{$\begin{array}{l}Y=-.092 Z_{1}-.211 Z_{2}+.060 Z_{3}-.099 Z_{4}+.105 Z_{5} \\
-.017 Z_{6}+.077 Z_{7}+.065 Z_{8}+2.500 \\
\quad R=.944, K^{2}=.891, F=72.83^{* * *} \\
* P<0.05, * * P<0.01, * * * P<0.01, F(8,71 ; 0.01)= \\
2.78\end{array}$} \\
\hline
\end{tabular}

the aroma quality than the first PC. Next, the relationships between the $8 \mathrm{PCs}$ and sensory score were analyzed by multiple regression analysis using BMD03R program as shown in Table IX. Eighty-nine per cent of variation contained in the sensory score could be explained by the calculated multiple regression model with high precision suggested by the high $F$ value of 72.8. According to the contributing proportion of each $\mathrm{PC}$ for the aroma quality, the second $\mathrm{PC}$ showed the largest value of $57.6 \%$ with the high F-value of 376.6 The seven PCs except for the sixth PC showed significant relation to the aroma quality.

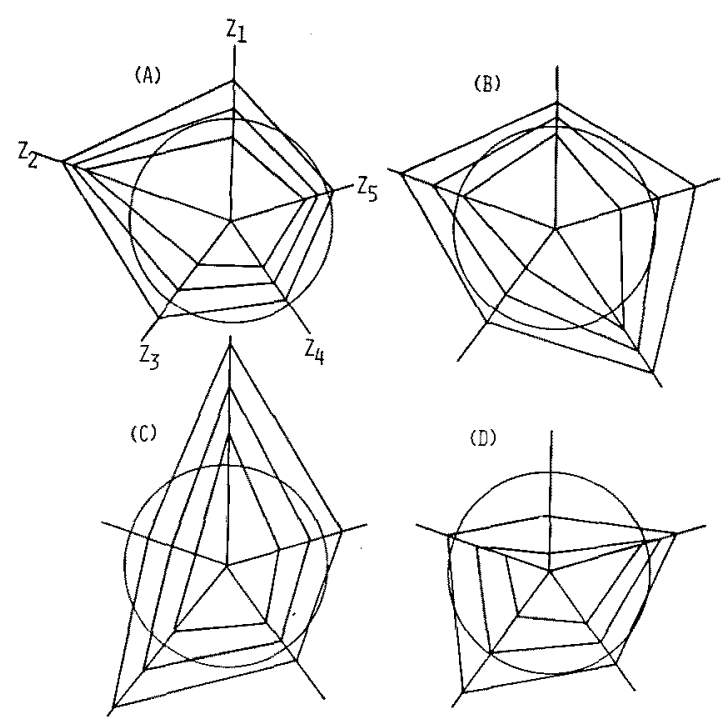

FIG. 7. Aroma Profiles Consist of Five Principal Components $\left(Z_{1 \sim \delta}\right)$.

Pentagonal aroma profiles of the four brands consist of major five PCs can clarify the difference among them as shown in Fig. 7. Profiles of brand $\mathrm{A}$ and $\mathrm{B}$ resembles each other, while the second $\mathrm{PC}$ of brand $\mathrm{C}$ and first $\mathrm{PC}$ of brand $\mathrm{D}$ greatly different from those of brand $A$, respectively.

\section{Discriminant analysis on $P C s$}

The eighty samples were plotted on the first and second PCs as shown in Fig. 8. However the samples belonging to the brand $\mathrm{C}$ and $\mathrm{D}$ respectively located in the quadrant III and IV, the samples of brand A and B could not be discriminated on them. In order to classify

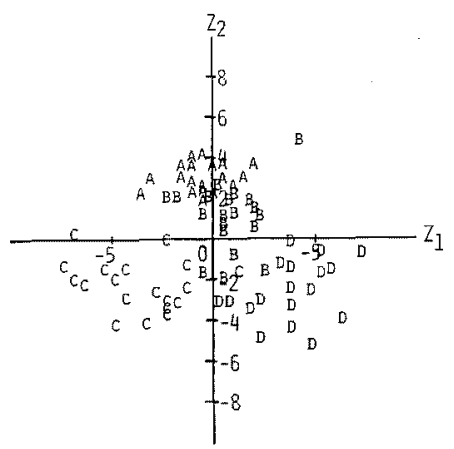

FIG. 8. Scattergrams of Samples on the First Principal Component $\left(Z_{1}\right)$ and Second Principal Component $\left(Z_{2}\right)$. 
Table X. F-Matrix Among Four Brands Calculated at Step 8

\begin{tabular}{crrr}
\hline \multirow{2}{*}{ Brand } & \multicolumn{3}{c}{ Brand } \\
\cline { 2 - 4 } & \multicolumn{1}{c}{$\mathrm{A}$} & $\mathrm{B}$ & $\mathrm{C}$ \\
\hline B & $45.48^{* * *}$ & & \\
$\mathrm{C}$ & $109.86^{* *}$ & $117.94^{* *}$ & \\
$\mathrm{D}$ & $132.58^{* *}$ & $57.59^{* *}$ & $169.82^{* *}$ \\
\hline$* *$ & $P<0.01, F(8,69 ; 0.01)=2.70$ &
\end{tabular}

Table XI. Number of Samples Classified INTO BRANDS AT STEP 8

\begin{tabular}{crrrr}
\hline \multirow{2}{*}{ Brand } & \multicolumn{4}{c}{ Brand } \\
\cline { 2 - 5 } & A & B & C & D \\
\hline A & 20 & 0 & 0 & 0 \\
B & 0 & 20 & 0 & 0 \\
C & 0 & 0 & 20 & 0 \\
D & 0 & 0 & 0 & 20 \\
\hline
\end{tabular}

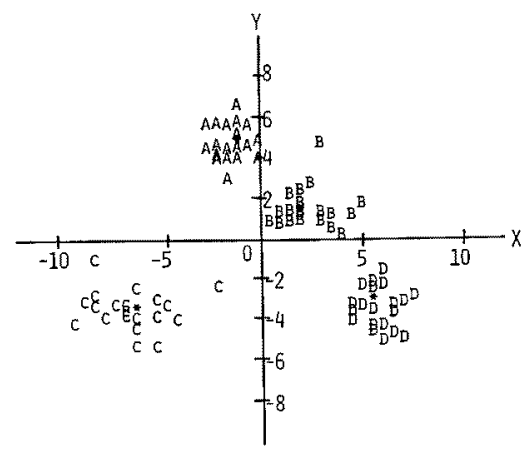

FIG. 9. Canonical Plot of Samples.

Canonical variables were calculated on the basis of principal components.

the samples on PCs, discriminant analysis was applied on the $8 \mathrm{PCs}$. The $F$-matrix among the four brands clearly indicated that there were highly significant difference among them as shown in Table $\mathrm{X}$. Eighty samples were classified into correct groups on the basis of caicuiated discriminant functions as shown in Table XI. The canonical variables for each sample calculated from eight $\mathrm{PCs}$ and each sample was plotted on the basis of the first and second canonical variables as shown in Fig. 9. Samples of brand $\mathrm{C}$ were located apart from those of other three brands. The scattergram seems that the wide distribution of samples in each brand on PCs in Fig. 8 were concentrated into the narrow region. Such a assembly of samples might be ascribed to the principle of discriminant analysis. Namely, discriminant functions are calculated in order to make the ratio of between-group variation to withingroup variation maximum.

These results of discriminant analysis on PCs evidently suggested the effective contraction of information contained in $\mathrm{GC}$ peaks to the 8 PCs without loss of significant information.

Acknowledgment. The author wishes to express his thanks to Prof. S. Koga of Tokyo University for the guidance in this work. The author also thanks Drs. D. Fukushima, M. Nagasawa, and A. Nubuhara for their support and encouragement, and Miss M. Yamazaki for her technical assistance.

\section{REFERENCES}

1) S. Goto, Eiyo to Shyokuryo, 26, 135 (1973).

2) N. Nunomura, M. Sasaki, Y. Asao, and T. Yokotsuka, Agric. Biol. Chem., 40, 485 (1976).

3) N. Nunomura, M. Sasaki, Y. Asao, and T. Yokotsuka, ibid., 40, 491 (1976).

4) N. Nunomura, M. Sasaki, Y. Asao, and T. Yokotsuka, ibid., 42, 2123 (1978).

5) T. Aishima and A. Nobuhara, ibid., 40, 2159 (1976).

6) T. Aishima and A. Nobuhara, Nippon Nôgeikagaku Kaishi, 51, 65 (1977).

7) T. Aishima, M. Nagasawa, and D. Fukushima, J. Food Sci., in press.

8) J. J. Powers and E. S. Keith, ibid., 33, 207 (1968).

9) L. Miltinovic, R. E. Bargman, K. Y. Chang, M. Chastain., and J. J. Powers, ibid., 35, 224 (1970).

10) A. Dravnieks, H. G. Reilich, J. Whitfield, and C. A. Watson, ibid., 38, 34 (1973).

11) A. Dravnieks and C. A. Watson, ibid., 38, 1024 (1973).

12) A. A. Bednarczyk and A. Kramer, 'Food Technol., 25, 1098 (1971).

13) A. A. Bednarczyk and A. Kramer, Chemical Senses and Flavour, 1, 377 (1975).

14) W. G. Jennings, ACS Symposium Series, No. 51 Flavor Quality: Objective Measurement, 1977, p. 1.

15) R. D. Carter and J. A. Cornell, ibid., $\{1977$, p. 104.

16) R. C. Lindsay, ibid., 1977 p. 89.

17) A.A. Williams, A.G.H. Lea, and C.F. Timberlake, ibid., 1977, p. 71.

18) Tanaka T. and Saito N., J. Ferment. Technol., 47, 780 (1969). 
19) UNIVAC Manual Class M, 1972, p. 53.

20) UNIVAC Manual Class R, 1972, p. 36.

21) N. Barylko-Pikielna and K. Metelski, J. Food Sci., 29, 109 (1964).
22) UNIVAC Manual Class R, 1972, p. 25.

23) UNIVAC Manual Class M, 1972, p. 15.

24) T. Yokotsuka, Y. Asao, and T. Sakasai, Nippon Nogeikagaku Kaishi, 41, 442 (1967). 